\title{
19
}

\section{Changing Paradigms: The Emergence of the Autism/Neurodiversity Manifesto}

\author{
Monique Craine
}

Throughout this chapter, I will be looking at the actions which led to the development of the Labour Party's Autism/Neurodiversity Manifesto in the United Kingdom (U.K.). I will explain where we are currently with the manifesto and what comes next. I will discuss why I chose the approach I took and who was helpful in moving the cause forward and I will also discuss some of the issues and barriers we encountered on our way. I will also define the terms neurodiversity and neurodivergent but firstly I would like to briefly introduce myself.

\section{A Bit About Me}

I am a fifty-year-old, married, mother of three; I am also a graduate and am currently in the early stages of launching a new self-employed venture.

M. Craine ( $\square)$

Cwmtwrch, UK

e-mail: monique@mccas.co.uk 
Prior to embarking on self-employment (for a second time), I had been employed in a variety of different job roles as well as having time at home raising the children; I had worked in everything from waitressing and sales, to running as a candidate for local elections and getting elected as a Liberal Democrat Borough Councilor, with all the responsibilities that go with that.

That's the positive "sales" version of me. There is another side to me which has coexisted alongside this resume version of me. During this time I have battled low self-esteem, severe anxiety attacks, depression, and the feeling that I just didn't fit in since I was in my early teens. I left school with hardly any qualifications, believing I had failed. I was faced with a career advisor who told me I was officially classed as "less able" and that I would never be able to gain a standard high school qualification; she told me I would most likely not be able to continue with education past age sixteen. I was basically told I was too stupid to ever learn. I was effectively written off at school.

Back then it was just accepted that I was one of those "slow" children. I often refer to my eleven years of compulsory schooling as an eleven-year assault on my self-esteem. I tended to disconnect in class, to allow my thoughts to focus on other more interesting details. The lessons did not interest me, and I struggled with basics like spelling and reading aloud. I knew I was different from the other children, not just in the way I thought but also in the way I moved, my behaviors, and even in the way I perceived the world around me.

From the age of five, I learned to mask (to pretend I was just like everyone else). At school I became selectively mute for a while, as I knew that if I talked people would call me weird; my solution was simple: "don't talk." I knew that my school work was not as good quality as the children who sat beside me so from age five I would hide my work so that the teachers and other pupils didn't notice my mistakes. I would then spend hours rewriting it at home so that I wouldn't be told off. In a way it is no surprise that I went through school without being diagnosed with any conditions. I did after all go out of my way to hide all my difficulties from my teachers. 


\section{Late Diagnosis-Diagnosing Difference}

Although I was not diagnosed with any conditions as a child, I was finally diagnosed with Dyslexia and scotopic sensitivity (light sensitivity), in my late twenties while studying at university. The knowledge I gained about how my dyslexic brain worked enabled me to stop punishing myself over the things I couldn't do and to instead discover new ways to work that took my different neurology into account.

I found that by adapting the way I worked, I could achieve much better results than I could while hiding my difficulties. I also found that I started to appreciate the way my visual memory worked; I had never realized that there were people who lacked my ability to visualize things. The way my visual memory works may make it an issue when it comes to interpreting two-dimensional letters on a page that represent a word, but it is pretty awesome when you can visualize processes in high definition, slow motion, and zooming into the detail. Once I realized that many dyslexic people have this same kind of high-definition visual memory. I realized that dyslexia gave me something awesome that I would not want to live without. Although I still struggled with reading and writing consistently, the simple truth is, I would rather have the amazing visual memory I have than be able to read and write with ease. Thus I felt proud to be dyslexic; I accepted I would need to put strategies in place to help me with the difficulties, but no way would I want to trade it!

I was very positive about being dyslexic even though I do find it a little embarrassing when my children by age six have found themselves correcting my reading to them at night.

The simple truth is I have never overcome my dyslexia, I have never learned to read accurately or consistently but I did learn to read slowly and repetitively for accuracy. I prefer to use specialist software to read things to me to ensure I am taking the correct meaning from text but given time, I can read. I was very positive about being dyslexic and although I still struggle with reading and writing, I am happy that with the right tech I can perform certain roles just as quickly as someone who can read and write fluently and is not dyslexic.

Dyslexia explained a lot in regards to the difficulties I encountered at school, but it didn't explain all my difficulties. After receiving my dyslexia 
diagnosis in 1997 (age 27), I still continued to seek medical support for my mental health issues. Anxiety was my "natural" state, and my immune system was so low I would catch everything. I was prescribed medication for the anxiety but it did nothing for me. I still struggled with my coordination-I was falling over every day, I was banging myself and breaking things constantly. I was struggling to maintain relationships that had meant the world to me for much of my life and I was unable to keep a job.

In 2012, I was diagnosed with dyspraxia/Developmental Coordination Disorder (DCD). Finally, I understood where my coordination issues and problems with movement came from. Again, post-diagnosis, I was able to create strategies to help me manage some of my difficulties. As before, I have not overcome being dyspraxic, I still have difficulties daily, but now that I account for my dyspraxia I suffer with fewer injuries.

It was also around this time I became active on the internet. I wanted to learn everything there was to learn about the way I functioned so that I could get my life back on track. Dyspraxia accounted for so much but by now I knew there was more than just dyspraxia and dyslexia going on, but I could still get no guidance on how to proceed. In 2013 one of my family members was put on the autism assessment pathway and once the doctors realized that there were cases of autism within my family I was able to get on the pathway for an Autism Spectrum Condition (ASC) assessment.

\section{Blogging and Other Internet Activities}

When I first started blogging in 2013 I was still pretty new to my own diagnoses and I had not yet been diagnosed as autistic. Through my early blogs I repeated what I had been told by professionals. I used their terminology about the conditions but I focused on the positives. I had a "can do" attitude and wrote about ways of improving areas we struggled with.

I believed that my dyslexia and DCD/dyspraxia were just down to the way I was wired. I was always going to have to take my differences into account but more often than not, the root cause of my difficulties were social barriers and my own poor mental health as my anxiety was a constant battle for me. I followed quite a few dyslexia groups on Facebook (FB), 
and would post supportive comments on parents' posts who were asking for help.

After getting my dyspraxia diagnosis I joined a few FB groups for dyspraxia too. My favorite group was called "Dyspraxia - Dyspraxic adults surviving in a non-dyspraxic world” (https://www.facebook.com/groups/ dyspraxiainadulthood). When I joined the group it only had about 400 members and it was very active as the founders had been using the group as research for their book of the same title.

In this Facebook group, I was meeting people with multiple neurodevelopmental diagnoses. Hearing their stories made me realize that my mental health issues, the burnout, the inertia, depression, and the constant anxiety I experienced, could have been brought on by other undiagnosed co-occurring neurological differences, as opposed to being due to a mental health illness. In the end I started my own blog site where I wrote strategy guides so I could post them to the group.

It's worth noting that when I started blogging it was mainly the adult dyspraxic online community I was talking to. However, I soon realized that my tips were not just relevant to dyspraxics, but to a lot of other groups too. The members who had other co-occurring developmental conditions were sharing my blogs in their other groups and similar feedback was coming from them. It was when my blog post on "Cleaning Your Home Made Easy" [1] went viral within the ADHD groups I realized our community had been segregated by a medical model which insisted on separating us from our natural peers and mentors.

The feedback I received for my blog surprised me because it had its biggest success within the ADHD groups. Neurodivergent (ND) adults were sharing it with "before and after" pictures of their houses. It was amazing and to this day I still get comments on how it has changed people's lives. This is the main reason I started talking to and about the Neurodivergent community instead of the segregated individual dyslexia, DCD, ADHD, Autism, etc., online groups. It is why I work toward unifying all the ND minority groups under one more natural banner.

By 2014 my blogs were really successful among the online ND communities in general. I was a well-known figure in the Dyspraxia (DCD) groups but my blogs were not going down as well with the autistic groups 
as they were with other ND groups. I was constantly getting negative feedback from autistic individuals. In the main, they loved my content but were frustrated by my terminology. Some of these people seemed unnecessarily aggressive over little things like my using person-first language or my using pathologized language to describe neurodiversity. They objected to my saying "person with autism," and for incorrectly using the term neurodiversity. A few even trolled me to some extent, posting every time I used any terms incorrectly. Despite these issues, the autistic individuals still seemed to like my content and as the general content was being well received I continued to write my guides and opinion pieces, but if you read my blogs in chronological order you will see how I slowly became aware of the issues surrounding the terminology I had used and over time totally changed the way I wrote about neurodiversity.

Although these autistic people were to some extent trolling me as they would post comments in every group I belonged to, they were not being nasty about it. They just felt the need to correct me every time they felt my terminology ruined an otherwise excellent article. I now consider many of these people among my best friends and am eternally grateful to those who first linked me to the work of Nick Walker. As that was the first time I came across a definition for neurodiversity which I actually understood and agreed with.

\section{Defining Neurodiversity}

Walker explained the history of the Neurodiversity movement, he had researched the subject in-depth and concluded that:

Neurodiversity is the diversity of human brains and minds - the infinite variation in neurocognitive functioning within our species. [2]

Walker also describes "how an individual cannot have a neurodiversity. That if someone's neurology diverges significantly from the typical majority, the correct term to use for them is neurodivergent." 
Walker's definition of neurodiversity made sense to me, it showed that autism, dyslexia, Tourette's syndrome, and other similar neurological developmental conditions were naturally forming variations within the human species and those of us with those developmental neurological brain-types were simply neurodivergent. We weren't broken or wrong, just different and thus had very different needs from most.

Understanding the terms neurodiversity and neurodivergent myself was only half the battle. I still had the problem that I wrote in person-first language, "person with autism," and I still used medical language to describe our differences-in terms of deficits and impairments. It was again the work of Walker who helped me understand why I struggled to convey a positive message regarding my own neurology.

In another article written by Nick Walker they state:

When it comes to human neurodiversity, the dominant paradigm in the world today is what I refer to as the pathology paradigm. The long-term well-being and empowerment of Autistics and members of other neurological minority groups hinges upon our ability to create a paradigm shift - a shift from the pathology paradigm to the neurodiversity paradigm. Such a shift must happen internally, within the consciousness of individuals, and must also be propagated in the cultures in which we live. [3]

In my early blogs I had followed the pathology paradigm, defining our differences by deficits and impairments. After reading the work of Nick Walker I got it. The pathology paradigm relied on a medical model, a system based on our (observable) presenting behaviors and which used a tick box diagnostic system, depending on whether our issues are mainly related to one cluster of ND-presenting difficulties or another. Having become an active member of quite a few online ND groups it seemed that the "main" diagnosis we got depended on the specialist we were first sent to in order to have our neurological differences diagnosed. I found that most of the group members in all the separate, segregated groups had co-occurring conditions and overlapping qualities. One diagnosis alone could not seem to define anyone's particular developmental history or help them find strategies suitable for their personal profiles. 
In the UK all developmental ND conditions are usually diagnosed and assessed by different specialists. Each specialist, be they a psychiatrist, educational psychologist, speech and language therapist, occupational therapist, or other, assesses each condition in isolation. Their knowledge and understanding of neurodiversity varies, and as a result we are not often sent for follow-on assessments for other presenting ND differences.

My mission had been to find out as much as I could about the different types of neurological development but I soon discovered that if you have multiple diagnoses you have to join multiple charities and groups to gain information relevant to you. I had by this point joined three leading charities and at least twenty different Facebook groups. I wanted information relevant to me in regards to my own dyslexia, dyspraxia/DCD, and autism which I had now been put on the assessment path for. It's a maze just trying to find others who have traveled your path but through the internet I was finding them, and they were finding me.

I stopped blogging for quite some time after discovering the work of Nick Walker, as I tried to research more on the topic of neurodiversity and the many different types of developmental neurodivergent conditions but it was also around this time I joined Autistic UK (https://autisticuk.org/), the leading autism organization in the UK that is run by, and for, autistic people. Autistic UK was engaged in the wider ND movement beyond autism. Although its main focus was in autistic rights, it was inclusive of all the other conditions, whereas most organizations would only deal with the one condition mentioned in their name. Autistic UK would look at the whole person and the many different ways they might function to ensure all their human needs were being taken into account. This was the main reason I wanted to join Autistic UK, as I wanted to find one organization who were keeping informed about issues affecting all ND groups.

By 2015 I had finally been diagnosed as being on the autism spectrum myself. I was by now a prominent and active member within many of the segregated ND online groups, sharing my blogs with each group separately. My business was not very successful in monetary terms but it was highly successful for my self-esteem, as I received comments and messages daily from grateful readers. I had just been shortlisted for the National Diversity Awards as a Positive Role Model for people with disabilities and it was at 
this point that I realized I needed to do more for the communities than just post top tip guides and opinion pieces on Facebook.

\section{From Dyslexia to Autism-Silencing Voices}

Talking about my autism diagnosis had different consequences to talking about my other ND differences. Autism was being seen differently to the other neurodevelopmental diagnoses. I had always referred to myself as being "dyslexic" but when I referred to myself as being "autistic" I was told off by parents and professionals as they felt it was insulting to put the condition before the person. Whereas I could talk positively about dyslexia, when I tried to do the same with autism I was being told that I was only a "self"-advocate and was nothing like their child. I was seen as an inspiration to the dyslexic and dyspraxic community but was shunned within the autism community despite being popular among the actually autistic group members.

In my eyes my autism was just a part of my individual brain wiring, no different from my dyslexia or DCD; it just ticked different boxes. There were many carers, parents, and others who worked with autistic people who told me that I had no right to speak on autism because their experience was of working with or raising autistic children who were also nonverbal or learning disabled. I received abuse daily from individuals who felt that I should shut up and not talk about autism positively, as in their view, it was a disease similar to cancer or diabetes which needed to be eliminated.

I soon discovered how hostile the world is toward autistics and realized that our voices are often silenced by people whose opinions seem to hold more weight within society. I also began to realize why the autistic audience had been so hard to please. They were fed up of being talked over.

I made many friends within the adult autistic online community as we all banded together to stop the hate. I had discovered that conditions like ADHD and autism were not seen as favorably as dyslexia, and hardly anyone had even heard of dyspraxia. Despite all these differences being natural forms of neurological development, it seemed as though autistics and ADHDers were being talked over and denied the right to shape their own futures, while dyspraxics remained invisible. 
I had a newfound fame within the internet-based ND groups because of my blogs and I had the ability to reach hundreds of people. I knew I needed to do something more.

\section{The Role that Shaped My Actions}

In 2002 I had been elected to local government as a Liberal Democrat Councilor and had been able to be part of the process for achieving positive change, albeit at a local level. I saw firsthand how long projects can take from conception to completion when they are done properly. During my time as a councilor, I sat on a number of council committees, and management boards for a number of external organizations. I worked with the police and local communities and set up a number of resident groups. I had gained valuable insight into how to give residents a voice and I wanted to help get these groups a voice.

I couldn't help but wonder whether I would have been elected back then had I known I was autistic and had I disclosed that, but that is a question for another day. The experience I took with me from having been an equal and active member of many forums meant I knew how to speak to the people at the top. Those in political office can really make a difference to our lives, but by 2015 I had no political allegiance of my own so I felt free to contact anyone and everyone that I thought would listen, no matter what party they belonged to.

\section{The Advocates Who Inspired Me}

It seemed to me that every day more recently diagnosed dyslexic, dyspraxic, and autistic adults were turning from using the internet to research their own neurological profile, to advocating for others who encountered similar barriers based on their neurology. From there some are unwittingly becoming active frontline campaigners for neurodivergent rights. When I was blogging for the dyslexic and DCD online community I worked with advocates like Sarah Chapman, owner of Operation Diversity (https:// 
operationdiversityacademy.co.uk/). Sarah champions neurodivergent talents and works hard to create a greater awareness of all developmental neurodivergent differences through her social enterprise.

I also worked with a number of dyspraxic advocates but by far the largest cohort of advocates was from within the autistic community. This seemed to me to be because dyslexic adults were allowed to talk about dyslexia even if they never mentioned any negative sides to it. For example, here in the UK we have the business leader Sir Richard Branson, who speaks openly about his dyslexia and how it helped him achieve greatness in his field. Richard Branson is an inspiration to many dyslexics, but it's harder to find autistic people who can talk about their experience of autism without others who claim to be part of the "autism" community shouting them down or pointing out that the individual speaking cannot or does not speak for their children who are in their views more seriously affected.

There seemed to be a barrier to actually autistic people standing up and talking about the issues of importance to the autistic community. We were not referred to as autism advocates, but as "self"-advocates; denied an opportunity to speak on topics of importance to us; and more often than not, denied payment for delivering talks. There seemed to be two communities at odds with each other where the autism community spoke over the voices of the actually autistic community. This injustice meant that autistic life coaches, bloggers, and advocates were used to being dismissed and at times attacked simply on the grounds of their autism being different to someone else's, but there were also more serious issues affecting the autistic community.

Through my online work I was introduced to individuals like Emma Dalmayne, the founder of Autistic Inclusive Meets (https:// autisticinclusivemeets.com/), who has taken on the battle against quack "cures" from individuals who claim they can help children "recover" from, or be completely "cured" of their autism. These people pray on vulnerable parents who do not understand autism and expose the autistic children and adults to abusive practices, such as drinking bleach in the form of MMS. Emma Dalmayne has led the fight to introduce specific legislation to prevent these types of abusive practices from being sold and used in the UK. Working with individuals like Emma also inspired me to do more than just blog. 
Internet-based groups like The Autistic Cooperative founded by Kieran Rose (www.theautisticadvocate.com) have links with autistic campaigners based all around the world. Neurodivergent community members are now finding each other through groups like this, supporting and teaching each other about how to campaign more effectively.

Many of these groups were being formed by autistic campaigners who were also multiply ND, so they were inclusive of members with other related conditions. A network of community leaders was forming on the internet where group leaders were trying to allow neurodivergent voices a safe space to talk. I saw and heard of many injustices through these groups, so I wanted to do something positive. Belonging to all the different ND groups guided my hand regarding how to take my activism out into the real world. I was focused on doing something that would have lasting positive effects for all our people so listening to who group members were talking about was essential to me.

In September of 2015, there had been a shuffle in leadership in the political parties and suddenly many in the ND groups were talking about wanting to reach out to one person. That person was Jeremy Corbyn Member of Parliament (MP), the newly elected Leader of the Labour Party (then and at the time of writing in early 2019, the main opposition party in the UK). In the autumn of 2015 individuals from all the ND groups were talking about how Corbyn seemed different, how if anyone was going to understand our plight it would be him. This intrigued me as it was coming from people who claimed to have lost faith in our political system, from supporters of other political parties as well as from Labour supporters. Jeremy Corbyn seemed to be appealing to many within the different ND communities, because he seemed to be approaching politics differently, so I addressed an open letter to him.

In the open letter I spoke about the emergence of an online-based neurodivergent community and stated that:

Although we are isolated within our geographical communities we have found others like us and formed huge communities on the internet. We gain support from each other and find ways to overcome hurdles together. [4] 
I congratulated Jeremy Corbyn for his appointment of a Shadow Minister for Mental Health and asked:

Jeremy Corbyn, you have created a Minister for Mental Health and I applaud you for that, it truly is an immensely important post in this era.

Can we ask that you also consider appointing a Minister for NeuroDiversity to work closely with the Minister for Mental Health? We are in need of political representation. [4]

An open letter signed by just one person is just a letter, from one person. I wanted to ensure I had the message right and that each of the different ND communities backed my call for the creation for a Shadow Minister for Neurodiversity.

The open letter received hundreds of comments in support in every ND group I shared it in. The ND community then seemed to take ownership of it and started sharing and retweeting it to their own contacts. It wasn't long before the letter had gone viral. I wanted as many comments as possible from members of the different neurodivergent communities before sending it to Jeremy Corbyn MP. It was essential to me that he sees it was the community speaking and not just me.

Between publishing the letter, coming out that I was autistic, my own general incompetence at promoting my paid work, the exploitative nature of the autism world, and my focus having turned to campaigning, I had not been able to make a success of my business.

I felt as though I was being forced to close my business because I could not make enough money, yet I was regularly being asked to attend autism events and speak for free. I remember posting something on my personal Facebook feed about how I was fed up of not having my time valued and how I would no longer support charities and organizations who claimed Autism in their title but who did not value our time enough to pay us. 


\section{The Butterfly Effect: Reaching the Right Person}

A Facebook friend commented on my post, saying I should meet her friend Janine Booth as she thought we had a lot in common. At this time I was still not very good at introducing myself to new people through the internet; my Facebook account was only used for my real-life family and friends. Yet I was already aware of Janine, having preordered her book "Autism Equality in the Workplace: Removing Barriers and Challenging Discrimination" [5]. I had also seen her website and enjoyed some of her poetry.

Janine was to my mind someone of note in the autistic community, she was a well-known author, activist, and campaigner whereas I was just a new internet blogger. I decided to private message Janine to introduce myself. I attached a copy of the open letter I had published so she knew a little about my own work and aspirations in the field.

Janine got straight back to me and asked that I forward the open letter to the Shadow Chancellor of the Exchequer, John McDonnell MP, as she felt he would be genuinely interested. The Shadow Chancellor is the direct opposition to the Government-appointed Chancellor of the Exchequer, the person responsible for the country's treasury. Although not currently in power having someone of this position on our side seemed essential if we wanted to move forward, I did as Janine suggested.

McDonnell responded to me, genuinely inquiring more about the request I had made in the open letter: the creation of a Shadow Minister for Neurodiversity. From there things moved very quickly. I was invited to meet John McDonnell at Portcullis House, in London to discuss my proposal further but because of my issues traveling I was not able to meet with him immediately. In the meantime Janine Booth had a book launch which John McDonnell was attending and after she asked him if he would support creating an autism manifesto, he announced his support for the creation of a Minister for Neurodiversity and an Autism Manifesto [6].

I was blown away by the announcement and was excited that I would soon be meeting with John McDonnell MP to discuss progressing matters. To be able to attend a meeting in London I needed my daughter to be my travel buddy. I had also asked Janine to come with me to the meeting for 
two reasons: one was because I was eternally grateful that she had pointed me in the direction of John McDonnell and secondly because I was scared to go in a building where I knew no one (although I had not physically met Janine by now we had corresponded a lot and I felt familiar with her).

\section{Conceptualizing an Inclusive Manifesto-The Meeting}

Our communal friend was right — we were certainly both on the same page; our responses to the questions from John McDonnell seemed to be exactly the same. During the meeting we discussed many areas of discrimination for the different ND communities we were attempting to represent. John McDonnell asked many questions. What he seemed to want to know was whether a Ministry for Neurodiversity would be enough to achieve the changes all the ND communities needed and whether an autism manifesto alone would be inclusive of all ND groups.

After talking about a variety of different issues in some depth we agreed that in reality much more was needed. We needed to combine my idea with Janine's and work toward achieving the best outcomes for all groups. We discussed how Government policies affect members of the ND community in every aspect of their lives, from health and education to housing, employment, and the judiciary system. By the time the meeting had come to a close, McDonnell had tasked Janine and myself to put together a team of ND individuals to start working on a fully inclusive manifesto to come back and put before him. McDonnell not only supported the "Nothing About Us Without Us" principle we desired, he put it front and center.

\section{The Creation of the Manifesto-Steering Group Actions}

Janine and I then put together the Labour Party Autism/Neurodiversity (LPA/ND) Manifesto Steering Group, made up of ND activists, advocates, academics, and campaigners. Our remit was to go to all the ND 
communities and with the communities' help, design a truly inclusive manifesto to present back to McDonnell.

Over the next few months we worked together to design a manifesto which was felt could bring about the kind of structural changes needed to create a more ND inclusive society. The Steering Group launched the LPA/ND draft manifesto in September 2016, at a fringe event of the Labour Party Annual Conference. McDonnell attended this event and spoke about how he was supporting the creation of the LPA/ND manifesto. He also spoke about how he had first been introduced to the world of autism through his constituency work, and about how he had been challenged by Janine Booth to do something about autism in regards to the workplace at a trade union event he had attended some years ago. My impression was that McDonnell had been thrust into the autism world through his political work long before my open letter arrived in his inbox. You can view John McDonnell's speech online [7].

Austin Harney (LPA/ND steering group secretary), spoke about his own lived experience of autism and why he was fully supportive of the manifesto. He stated:

When I received the diagnosis, the authorities recommended that I was taken away from mainstream education against my wishes. The top professional medical experts stated that I had sub - normal intelligence that was unfit for mainstream society, education and employment. I was sent to an Autistic compound. [8]

Austin, like so many of us, was able to prove these doctors wrong and is now a civil servant as well as being a member of the national executive committee for its trade union, PCS (Public and Commercial Services) Union.

Janine Booth spoke of the impact Neurodiversity training was having in the workplace, how it was showing real benefits, not just to the ND staff but to other staff and clients too. She then outlined the core principles: the social model of disability, the neurodiversity approach, opposition to austerity, socialism, democracy, solidarity, and the Nothing About Us Without Us principles which had helped us construct the document we 
were setting out before the delegates. She then outlined the document in full [9].

After the launch, we created a Facebook Page (https://m.facebook.com/ LPANDmanifesto/) so that the segregated online communities could add their input easily through their Facebook accounts. Janine ran Neurodiversity training events and we attended meetings and ND events, so that we could between us all obtain more feedback from the many varied, segregated ND communities.

Joseph Redford had been involved in setting up or running many autistic community-building events prior to joining the LPA/ND Manifesto group. He had worked with Autscape, an event run for and by autistic people. Joseph had also worked on Autistic Pride in Hyde Park, an event which started in London and which in 2018 saw autistic people and their families attend Autistic Pride events in cities all over the country. Joseph was able to take the Manifesto and gather valuable feedback from many within the autistic community through these activities and events.

Annie Morris facilitated all our meetings and also set up and monitored the Neurodiversity Manifesto Website for the group (https:// neurodiversitymanifesto.com). We also were lucky to have noted academics available to the steering group. Dr. Damian Milton and Dr. Dinah Murray were able to help us research any controversial issues in more depth.

In 2017 the steering group was in the process of gathering feedback to ensure all issues had been considered in the draft document. We wanted to ensure we had not left any groups unrepresented and we wanted to do a good job. We were not due for a General Election in the UK until 2020 and we wanted to produce a document that was well-thought-out so the Labour Party would have no problems adopting it before the next General Election. But this all coincided with massive political change taking place in the UK as the vote to leave Europe had taken place in 2016 and the political landscape was changing. The Conservative Government changed its leadership and Theresa May was appointed the new Prime Minister. In June 2017 a snap General Election was called and we again found ourselves at the ballot boxes.

When the election was called the steering group collated all the information we had gathered. The draft manifesto was then adapted and submitted to McDonnell just before the official Labour Manifesto was itself 
published. All of us on the LPA/ND Manifesto steering group knew there was no time to have the full manifesto included in time for that election, but as McDonnell had seemed to understand our issues and had attended steering group meetings when he could, we hoped that some of our more general aims would have been brought up.

The official Labour Party Manifesto 2017, "For The Many Not The Few" [10], included some of the core principles requested in the draft A/ND manifesto. The Labour Party Manifesto made it clear that the Labour Party desired an autism-friendly UK, that they wanted to implement the social model of disability, and look to resolve disability issues created by lack of accommodations rather than expecting the change to come from the disabled person. It even mentioned neurodiversity.

In September 2017 we were ready to host the Autism/Neurodiversity event at the Labour Party Conference. A copy of the drafted manifesto was left on all the delegates chairs so they could refer to it throughout. A copy of this can be found online [11].

I Chaired this event, and had the pleasure of introducing McDonnell, who this time spoke of how proud he was of the work Janine and the whole of the steering group had put into creating the Manifesto and again stated his full support for it.

Emma Lewell-Buck MP, the only openly dyspraxic Member of Parliament then spoke about what it is like being a dyspraxic politician. Other politicians and members of the steering committee also spoke about how the Autism/Neurodiversity Manifesto would impact the different ND groups and how that could benefit society.

We had talks by dyslexics, autistics, dyspraxics, and a very vivid and powerful talk by Terry Laverty, a core member of the Steering Group, who spoke on the topic of ADHD. Terry spoke about what it is like having a mind that works so differently to most and the discrimination faced by ADHD adults.

The event was very well attended and support for the manifesto was unanimous. One of the comments from the delegates which stuck with me was that they had never been in a room with so many neurodivergent people in one place. It really was an amazing feeling to be in a room full of our actual peers. 


\section{Where We Are Now-The Present}

In 2018 we ran another successful conference where we introduced our critical appendix on Applied Behavioral Analysis (ABA) which was also incredibly well received [12]. Shortly later Janine and myself reported back to John McDonnell MP, to present the final manifesto to him in detail [13]. John McDonnell fully supports the manifesto and is keen to see the whole document officially adopted by the Labour Party and has explained how we can now go through the right channels to get it approved by the National Executive.

\section{Launch of Neurodivergent Labour}

I learned through my time as a borough councilor that all projects take time: there is no guarantee that just because you start a project, you will still be there when it is approaching completion. Therefore, the best projects are the ones you can walk away from knowing that you have already got the ball rolling in the right direction.

I feel proud to know that if I walked away soon I would have left behind me a democratically formed organization who have pledged to promote the A/ND manifesto and to fight for the rights of neurodivergent people. I have faith in this organization being a force for positive change.

On February 9, 2019, I saw politics on the brink of a paradigm shift as it opened the door to neurodivergent voices. John McDonnell again spoke of his support for the work we had done and the ambitions we had to make the Party more accessible to us. As the Disability News Service later reported, John McDonnell said:

As I keep repeating, this is not about electing a group of MPs who will go off and do it for us. That will never work, it never has and it never will. This is about when we go into government, we all go into government, so we draft our manifesto, we secure commitments from the bulk of the Labour Party through the normal policy making process and then when we go into government, we all work on the detail of the implementation itself. [14] 
Hearing McDonnell speak filled me with confidence. Knowing that it is no longer just individual voices trying to be heard, but a movement of people who are uniting under the Neurodivergent banner.

I am eternally grateful that my open letter to Jeremy Corbyn, MP, fell into the hands of Janine Booth. I'm so glad she had the political awareness to make it much bigger than it was, by getting it to the best person to read it, and for pushing for a manifesto. I am eternally grateful to John McDonnell for understanding the need to create a ND inclusive manifesto so we can all be supported, and for allowing us, the ND individuals, to lead throughout the process of inception, construction, and delivery.

I hope that other ND advocates are writing to people they think might help. Despite the internet trolls we have to contend with, there are actually a lot of good people out there and there are some amazing allies still to be made. It is amazing what a simple letter can lead to. My aim was to start a ball rolling, to start something that I could eventually walk away from knowing that the momentum alone would keep it going. I wanted to start a conversation that included us at all levels. What I hadn't realized at the time, was that hundreds of ND advocates are out there doing the exact same thing. One person at a time, perspectives are changing, and paradigms are shifting. As more and more advocates find each other and work together our voices are getting heard.

\section{References}

1. Craine, M. (2014, July 5). Cleaning your home-Made easy (Web log post). Retrieved from http://needtosay.weebly.com/blog/cleaning-yourhome-made-easy.

2. Walker, N. (2014, September 27). Neurodiversity: Some basic terms \& definitions (Web log post). Retrieved from http://neurocosmopolitanism.com/ neurodiversity-some-basic-terms-definitions.

3. Walker, N. (2013, August 16). Throw away the master's tools: Liberating ourselves from the pathology paradigm (Web log post). Retrieved from http:// neurocosmopolitanism.com/throw-away-the-masters-tools-liberatingourselves-from-the-pathology-paradigm. 
4. Craine, M. (2015, September 16). An open letter to Jeremy Corbyn (Web log post). Retrieved from http://needtosay.weebly.com/blog/an-open-letter-tojeremy-corbyn.

5. Booth, J. (2016). Autism equality in the workplace: Removing barriers and challenging discrimination. Philadelphia, PA: Jessica Kingsley Publishers.

6. Weaver, M. (2016, May 31). Labour to appoint a shadow minister for neurodiversity. The Guardian. Retrieved from https://www.theguardian.com.

7. McDonnell, J. (2016, September). LPA/ND launch speech [Video file]. Retrieved from https://videopress.com/v/5C8MnEvD.

8. Harney, A. (2017, June 3). A post from Austin Harney (Web log post). Retrieved from https://neurodiversitymanifesto.com/2017/06/06/apost-from-austin-harney-a-member-of-this-steering-group.

9. Neurodiversity Manifesto. (2016, September 22) Neurodiversity manifesto: Labour Party launch (Manifesto). Retrieved from https:// neurodiversitymanifesto.com/2016/09/22/neurodiversity-manifestolabour-party-launch.

10. Labour Party. (2017). For the many not the few (Manifesto). Retrieved from https://labour.org.uk/wp-content/uploads/2017/10/labourmanifesto-2017.pdf.

11. Labour Party Autism/Neurodiversity Manifesto Steering Group. (2017, September 15). The Labour Party Autism/Neurodiversity Manifesto (V.2, 2017) (Manifesto). Retrieved from https://neurodiversitymanifesto.com/2017/09/ 15/the-labour-party-autism-neurodiversity-manifesto-v-2-2017.

12. Milton, D. (2018, September 15). A critique of the use of Applied Behavioural Analysis (ABA): On behalf of the Labour Party Autism/Neurodiversity Manifesto Steering Group (Manifesto appendix). Retrieved from https://neurodiversitymanifesto.com/2018/09/15/labour-party-autismneurodiversity-manifesto-2018-please-see-our-final-draft-on-page-3.

13. Labour Party Autism/Neurodiversity Manifesto Steering Group. (2018, September 18). Labour Party Autism/Neurodiversity Manifesto: Final draft version (Manifesto). Retrieved from https://neurodiversitymanifesto.com/ 2018/09/18/labour-party-autism-neurodiversity-manifesto-final-draftversion-2018.

14. Pring, J. (2019, February 14). Launch of Neurodivergent Labour 'could be milestone in fight for rights and equality'. Disability News Service. Retrieved from https:/www.disabilitynewsservice.com. 
Open Access This chapter is licensed under the terms of the Creative Commons Attribution 4.0 International License (http://creativecommons.org/licenses/by/ $4.0 /$ ), which permits use, sharing, adaptation, distribution and reproduction in any medium or format, as long as you give appropriate credit to the original author(s) and the source, provide a link to the Creative Commons license and indicate if changes were made.

The images or other third party material in this chapter are included in the chapter's Creative Commons license, unless indicated otherwise in a credit line to the material. If material is not included in the chapter's Creative Commons license and your intended use is not permitted by statutory regulation or exceeds the permitted use, you will need to obtain permission directly from the copyright holder. 